\title{
Egg to juvenile period, generation time, and the evolution of larval type in marine invertebrates
}

\author{
Jon. N. Havenhand \\ University of Washington, Friday Harbor Laboratories, Friday Harbor, Washington 98250, USA \\ and \\ School of Biological Sciences, Flinders University, GPO Box 2100, Adelaide 5001, Australia*
}

\begin{abstract}
Many hypotheses have been put forward to explain the evolution of different larval types in marine invertebrates. These hypotheses have generally ignored the impact which the larval (developmental) type can have on the adult stage of the life cycle. A conceptual model presented here shows how reduction of the pre-metamorphic, or 'egg-to-juvenile' period either increases size at reproduction [by increasing the benthic (post-metamorphic) development period in the case of species with fixed duration life cycles], or decreases overall generation times (in species with fixed size or age at reproduction, and variable life cycle duration). In either case the net result is an increase in fitness. A simple analytical version of this model is derived and is illustrated with data from 2 species of nudibranch mollusc. The model reveals an 'optimal' egg-to-juvenile period (where the intrinsic rate of increase $(r)$ is maximised] for all life-cycle durations modelled. Reduction of the egg-to-juvenile period leads to an increase in $r$ in all cases except when egg-to-juvenile period is very short. At egg-tojuvenile periods typical of species with feeding larvae, increases in $r$ may be considerable (a reduction in egg-to-juvenile period from $100 \mathrm{~d}$ to $90 \mathrm{~d}$ yields a 4 to $13 \%$ increase in $r$ ). Available evidence from several taxa indicates that developmental type and egg-to-juvenile period are correlated, such that species with non-feeding larvae tend to have shorter egg-to-juvenile periods. Consequently, the selective pressures to reduce egg-to-juvenile period which are illustrated by this model highlight a previously overlooked pressure for the evolution of non-feeding larvae in marine invertebrates.
\end{abstract}

\section{INTRODUCTION}

The evolution of different larval types in marine invertebrates has interested marine biologists since the pioneering work of Thorson (1946). It is now generally accepted that in most phyla the pelagic feeding (i.e. planktotrophic) larva is ancestral, and that nonfeeding (lecithotrophic) larvae - which may or may not possess a pelagic phase - are an evolutionary derivative (e.g. Jägersten 1972, Strathmann 1985). Theoretical considerations of the respective advantages of these larval types have stressed the importance of dispersal, gene-flow, energetics, predation, adult body size, phylogeny, and trophic relationships (reviews by Day \& McEdward 1984, Grahame \& Branch 1985, Strathmann 1986). All of these works

\footnotetext{
-Address for correspondence
}

have emphasised the importance of the larva as an integral component in the evolution of life-history strategies; however it is only recently that life-history models have included all stages of the life cycle (e.g. Roughgarden 1989).

Despite the recent resurgence of interest in larval ecology, most workers have overlooked the effects that larval type may have on the juvenile and adult stages of the life cycle. Partly this arises from the implicit assumption that the embryonic and larval development period represents a small proportion of the complete life cycle and that therefore these stages have little influence on the evolution of the life cycle and life-history of marine organisms. However, evidence from recent empirical studies by Levin et al. (1987) and Miller \& Hadfield (1990) has indicated that the demographics of later stages in the life cycle may be affected substantially by the length of the premetamorphic development period. 
The relationships between development period, larval type and egg-size have been the subject of much debate (Vance 1973, Underwood 1974, Strathmann 1977. Christiansen \& Fenchel 1979, Emlet et al. 1987). Although embryonic or larval development times do not individually bear close relationships to egg size (Underwood 1974, Emlet et al. 1987), a survey of the literature shows that in most phyla larval type and total development times from egg to immediately post-metamorphic juvenile (i.e. embryonic plus larval development times) are correlated: viz. pelagic lecithotrophy and non-pelagic lecithotrophy ('direct' development) yield a shorter egg-to-juvenile period (EJP) than planktotrophic development (data in Todd 1981, Calow 1983, Emlet et al. 1987, Strathmann 1987, Rumrill 1990; see Fig. 1).

In one of the few studies which have drawn attention to the link between the evolution of larval type and post-settlement demographics, Todd \& Doyle (1981) suggest that the evolution of larval types may be influenced by the temporal separation of optimal times of reproduction and settlement. Their 'settlement-timing hypothesis' rests on the relationship between larval type and EJP outlined above (Todd \& Doyle 1981). In presenting this hypothesis, they noted that previous models had failed to account for the different developmental periods associated with each larval type. Ayal \& Safriel (1982) stressed this very point in a methodological paper in which they analysed the influence of the larval period on the instantaneous population growth rate $(r)$. They concluded that the higher 'cost' of planktotrophy (with respect to non-pelagic lecithotrophy) derived partly from longer generation times, although they did not closely investigate the impact of larval type on generation time (Ayal \& Safriel 1982). More recently, Miller (in press) has highlighted the

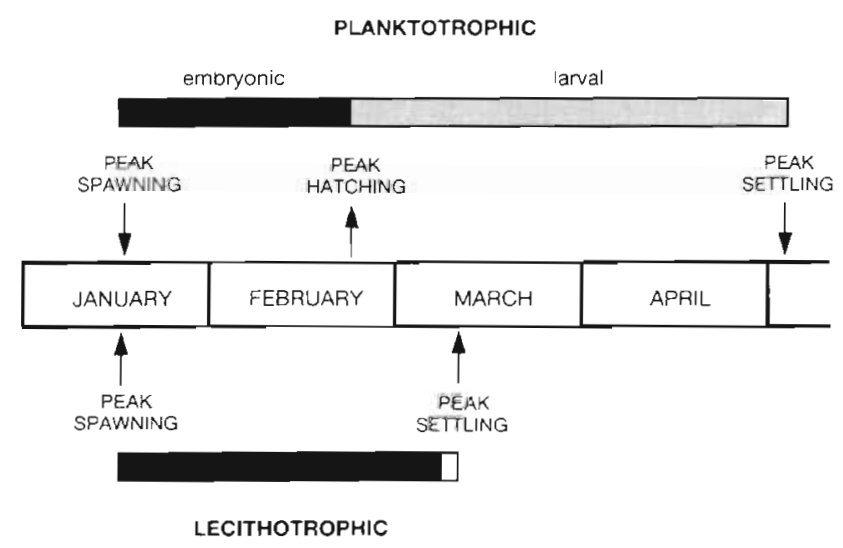

Fig. 1 Measured egg-to-juvenile period for a nudibranch mollusc with planktotrophic development (upper bar) and estimated time for pelagic lecithotrophic development (lower bar). See text. (After Todd \& Doyle 1981) demographic costs of delayed metamorphosis in species with short life cycle durations.

In this paper I present a model of the demographic consequences of varying the egg-to-juvenile period on the life cycle of marine invertebrates. Two models are described: a conceptual model of general applicability, and a detailed mathematical derivation for semelparous species with fixed life-cycle duration. An example is provided from 2 species of nudibranch mollusc which exhibit different larval types, different EJPs, and different types of post-metamorphic growth curve. The model illustrates how variation in EJP can directly affect growth and reproductive output of postlarval stages of the life cycle, and provides estimates of changes in fitness which accrue from this. The model is not intended to provide accurate estimates of absolute fitness, but rather to demonstrate the magnitude of fitness differences which can derive from different EJPs.

In order to generate these models, several simplifying assumptions have been made: all individuals exhibit complete hermaphroditic semelparity (all individuals reproduce and all reproduction occurs on the last day of adult life); pre- and post-metamorphic growth rates are each fixed (i.e. time-invariant); pre- and postmetamorphic mortality rates are similarly fixed; and reproductive output is directly proportional to body size. Justification of these assumptions - and potential errors arising from them - are discussed below.

\section{SELECTION FOR DECREASED EGG-TO-JUVENILE PERIOD}

According to Werner (1986), the optimal time to metamorphose is determined by a trade-off between the ratios of mortality to growth rates in the premetamorphic and post-metamorphic habitats: if mortality/growth is higher in the pre-metamorphic habitat, then selection will favour early metamorphosis and early occupation of the post-metamorphic niche (in which mortality is lower and/or growth is greater). It is almost axiomatic that survivorship during the planktonic period is lower than during benthic stages of the life cycle (e.g. Rumrill 1990), however the appropriate pre- and post-metamorphic growth and mortality schedules necessary to test Werner's model are not readily available for any marine invertebrate. Notwithstanding the benefits which may come from having a dispersive planktonic phase (Grahame \& Branch 1985, Strathmann 1985, 1986), it is widely held that the 'costs' of the planktonic period exert a selective pressure to reduce the duration of the larval period. [Even in species which possess feeding larvae this survivorship 'cost' is often assumed to offset any advantages 
which might occur from larval growth; see Roughgarden (1989), for an overview of the effects of larval growth and mortality on the evolution of marine invertebrate life histories].

Therefore, in a hypothetical semelparous species with a strictly annual (and seasonal) life cycle, reduction of the EJP would increase the post-metamorphic period and thereby release additional time for growth and development of the juvenile/adult. If size at metamorphosis remained constant (i.e. larger eggs gave rise to larger hatchlings with shorter EJPs), size at reproduction should be correspondingly greater due to the increased post-metamorphic period. In the absence of systematic variation in other life-history characteristics this greater size at reproduction would be translated into increased reproductive output relative to that obtainable by species with longer EJPs. In species which do not exhibit a fixed time (or season) of reproduction, but instead reproduce at a given body size, the effect of reducing EJP would be to reduce overall generation time.

In both of the above cases the net result would be to increase the intrinsic growth rate $(r)$ of the lineage: i.e. representation of that lineage (genotype) in future generations would be greater than for lineages with longer EJPs.

It is worth noting at this point that although measurements of $r$ are frequently referred to as 'adaptedness' or 'absolute fitness' (Endler 1986) these latter terms are applied to absolute $r$ values derived for whole populations or species. However, natural selection can only operate on differences in adaptedness (ibid.). As we shall see, $r$ values are obtained here for differing combinations of life-history characters which correspond to different hypothetical lineages within a population. These $r$ values are used comparatively. Therefore these changes in intrinsic rate of increase $(r)$ are referred to in this work as 'fitness'. This conforms to the definitions of 'fitness' given by Lincoln et al. (1982) and Endler (1986).

To rigorously examine the effect of egg-to-juvenile period on fitness, and its sensitivity to changes in a variety of larval and life-history characteristics, I present a mathematical model. This model has 2 forms which differ only with respect to post-larval growth; in the first post-metamorphic growth is linear over time (i.e. the growth rate is constant), whereas in the second postmetamorphic growth is exponential over time (i.e. the specific growth rate is constant). These 2 growth patterns were chosen for their applicability to 2 species of nudibranch mollusc for which sample data are available, and because they are representative of growth curves for many semelparous species (see below). In both cases all reproduction occurs after a given time (on the last day of the life cycle), not at a given body size.

\section{THE MODEL}

Let $\theta$ be that proportion of the total life cycle $(T)$ which is taken up by development from oviposition to metamorphosis. Then $\theta T$ is equal to the egg-tojuvenile period (EJP), and the total post-metamorphic (benthic) period is equal to $T(1-\theta)$. If $W_{0}$ represents the weight of a larva at hatching, then the weight at metamorphosis will be given by:

$$
W_{0} e^{\gamma \theta T}
$$

where $\gamma$ is the mean specific growth rate from oviposition to metamorphosis (i.e. the larval growth rate discounted for the proportion of the EJP which is spent in embryonic development. For convenience, this term will be referred to as 'larval growth rate'). If, after metamorphosis, the summed mass of both somatic and (stored) reproductive tissues is assumed to increase linearly at a rate of $g$ per day, then the weight at reproduction will be:

$$
W_{0} \mathrm{e}^{\gamma \theta T}+g T(1-\theta)
$$

Multiplying this term by the weight-specific fecundity, $\rho$, will therefore yield the expected lifetime fecundity. However, $\rho$ will not be fixed but will vary with EJP. This is because shorter EJP correlates with non-feeding larvae which, in turn, tend to hatch from larger ova (refs, above). Consequently reduction of EJP will require larger eggs, which (given a constant overall volume of reproductive material) will cause reduced fecundity. Thus, $\rho$ will depend on the relationship between ovum size and EJP. Therefore if $\varepsilon$ is the ovum diameter and $\omega$ represents the overall (weight-specific) volume of ovum material produced, then weight-specific fecundity, $\rho$, will be given by:

$$
\rho=\frac{\omega}{(4 / 3) \pi(\varepsilon / 2)^{3}}
$$

Since all reproduction occurs on the last day of the life cycle, we can now obtain a term for total lifetime fecundity, $f$, by combining the 2 equations given above:

$$
f=\rho\left[W_{0} \mathrm{e}^{\gamma \theta T}+g T(1-\theta)\right]
$$

In order to determine the effective fecundity of an individual (or more strictly, the basic reproductive rate, measured as reproduction per individual per cohort; $R_{0}$ ), we must also take account of both pre- and postmetamorphic mortality. If $\mu_{\mathrm{I}}$ is the pre-metamorphic mortality rate (in this case the weighted mean of embryonic and larval mortality rates), and $\mu_{\mathrm{b}}$ is the post-metamorphic (benthic) mortality rate, then the basic reproductive rate becomes: 


$$
R_{0}=\rho \mathrm{e}^{-\mu_{1} \theta T} \mathrm{e}^{-\mu_{\mathrm{b}} T(1-\theta)}\left[W_{0} \mathrm{e}^{\gamma \theta T}+g T(1-\theta)\right]
$$

In this formulation the first exponential term represents pre-metamorphic mortality and the second represents post-metamorphic mortality. This model assumes implicitly that individuals of all sizes are reproductively mature. To do this is biologically unrealistic however: in almost all species reproductive maturity is achieved at some size or time after metamorphosis. This can be included by subtracting from. Eq. (1) a minimum weight at maturity, $W_{\text {m. }}$ Any body size (and by definition the corresponding life cycle duration) which is less than $W_{\mathrm{m}}$ is insufficient to permit reproduction. Consequently the reproductive rate becomes:

$$
R_{0}=\rho \mathrm{e}^{-\mu_{1} \theta T} \mathrm{e}^{-\mu_{\mathrm{b}} T(1-\theta)}\left[W_{0} \mathrm{e}^{\gamma \theta T}+g T(1-\theta)-W_{\mathrm{m}}\right]
$$

Clearly this relationship holds only if:

$$
\left[W_{0} \mathrm{e}^{\gamma \theta T}+g T(1-\theta)-W_{\mathrm{m}}\right] \geq 0
$$

Conventionally, the intrinsic rate of natural increase ( $r$ ) is given by:

$$
r=\frac{\ln R_{0}}{\tau}
$$

where $\tau$ is generation time (e.g. Begon et al. 1986). The present model assumes all organisms are semelparous and that all reproduction occurs on the last day of the life cycle. Therefore life cycle duration and generation time are the same $(\tau=T)$. Thus, combining Eqs. (2) and (3) gives the intrinsic rate of increase per individual per unit time:

$$
r=\frac{\ln \left\{\rho \mathrm{e}^{-\mu_{1} \theta T} \mathrm{e}^{-\mu_{\mathrm{b}} T(1-\theta)}\left[W_{0} \mathrm{e}^{\gamma \theta T}+g T(1-\theta)-W_{\mathrm{m}}\right]\right\}}{T}(4)
$$

If, instead of linear growth, we assume that postmetamorphic growth is exponential at a specific growth rate of $g^{\prime}$ per day, then following the derivation shown above the intrinsic rate of increase will follow the expression:

$$
r=\frac{\ln \left\{\rho \mathrm{e}^{-\mu_{1} \theta T} \mathrm{e}^{-\mu_{\mathrm{b}} T(1-\theta)}\left[W_{0} \mathrm{e}^{\gamma \theta T}+\mathrm{e}^{g^{\prime} T(1-\theta)}-W_{\mathrm{m}}\right]\right\}}{T}(5)
$$

\section{EVALUATION OF THE MODEL - SAMPLE DATA}

Data were obtained from studies on 2 species of nudibranch mollusc, Adalaria proxima (A\&H) and Onchidoris muricata (Müller), and from the literature (Table 1). Both species of nudibranch are annual and semelparous. In common with most opisthobranchs, individuals are simultaneous hermaphrodites with internal fertilisation and reciprocal copulation. Ova are deposited in benthic spawn masses, where embryonic

\begin{tabular}{|c|c|c|c|c|}
\hline Parameter & Symbol & $\begin{array}{l}\text { Adalaria proxima } \\
\text { (lecithotrophic) }\end{array}$ & $\begin{array}{l}\text { Onchidoris muricata } \\
\text { (planktotrophic) }\end{array}$ & Units \\
\hline Weight at hatching & $W_{0}$ & $0.001^{\mathrm{a}}$ & $0.0002^{b}$ & $\mathrm{mg} \mathrm{dwt}$ \\
\hline Larval (pre-metamorphic) growth rate & $\gamma$ & 0 & $0.095^{b}$ & $\mathrm{~d}^{-1}$ \\
\hline Larval (pre-metamorphic) mortality rate & $\mu_{1}$ & $0.05^{6}$ & $0.15^{b}$ & $d^{-1}$ \\
\hline \multicolumn{5}{|l|}{ Post-metamorphic growth rate } \\
\hline (Linear model) & $g$ & $0.156^{\mathrm{c}}$ & - & $m g d w t d^{-1}$ \\
\hline (Exponential model) & $g^{\prime}$ & - & $0.0238^{c}$ & $d^{-1}$ \\
\hline Benthic (post-metamorphic) mortality rate & $\mu_{\mathrm{b}}$ & $0.001^{\mathrm{b}}$ & $0.001^{\mathrm{b}}$ & $d^{-1}$ \\
\hline Weight at maturity & $W_{\mathrm{m}}$ & $10.0^{\mathrm{c}}$ & $5.0^{c}$ & $\mathrm{mgdwt}$ \\
\hline Weight-specific volume of ovum material produced ${ }^{d}$ & $\omega$ & $8.44 \times 10^{9} c$ & $2.17 \times 10^{10 c}$ & $\mu \mathrm{m}^{3}$ \\
\hline Ovum diameter $^{e}$ & $\varepsilon$ & (variable) & (variable) & $\mu \mathrm{m}$ \\
\hline Weight-specific fecundity ${ }^{d}$ & $\rho$ & (variable) & (variable) & - \\
\hline Life cycle length & $T$ & $365 /$ (variable) & 365/(variable) & $\mathrm{d}$ \\
\hline Proportion of life cycle taken up by egg-to-juvenile period & $\theta$ & (variable) & (variable) & - \\
\hline Intrinsic rate of natural increase & $r$ & (result) & (result) & ind $^{-1} \mathrm{~d}^{-1}$ \\
\hline \multicolumn{5}{|c|}{ 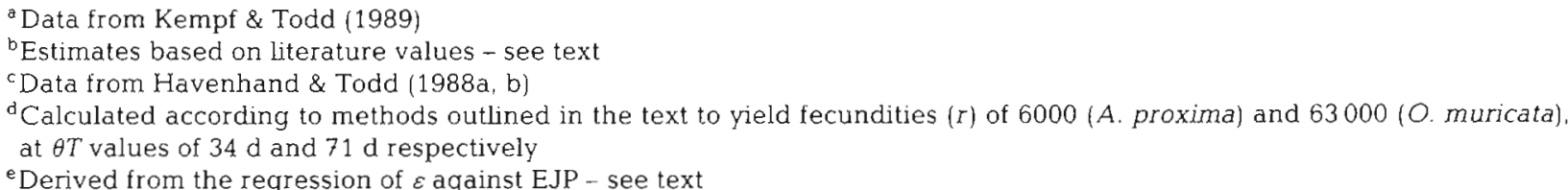 } \\
\hline
\end{tabular}
development takes place prior to hatching of the planktonic veliger larva. The larvae of $A$. proxima are non-feeding (lecithotrophic), and metamorphose within a few days of hatching (Kempf \& Todd 1989). In

Table 1. Parameters and input variables for the mathematical models 
contrast, the larvae of $O$. muricata are planktotrophic and require an extended period of feeding and growth in the plankton before they are competent to settle and metamorphose (Todd \& Havenhand 1985, Havenhand 1986). The parameter and variable values used are given in Table 1.

In order to evaluate the mathematical model, the weight-specific fecundities of both species of nudibranch were determined. The overall relationship between ovum diameter and egg-to-juvenile period (EJP) was obtained from data for 31 species of opisthobranch mollusc (Hadfield \& Switzer-Dunlap 1984, Strathmann 1987). Data for these species were standardised to a temperature of $10^{\circ} \mathrm{C}$ using the equation of Todd \& Doyle (1981) prior to analysis. This temperature lies close to the mean ambient temperature experienced by Adalaria proxima and Onchidoris muricata in the field. Standardised data (Table 2) yielded a highly significant correlation between log ovum size and $\log$ EJP ( $r=0.654, n=31, p<0.001)$. A geometric mean estimator of a Model II regression through these data gave the relationship:

$$
\text { Ovum Diameter }=1511.71(E J P)^{-0.6713}
$$

The parameter $\omega$, the total weight-specific volume of ova material produced, was determined iteratively so that weight-specific fecundity, $\rho$, was equal to the observed mean fecundity for adult $A$. proxima and O. muricata at their respective EJP's (see Table 1).

Although the data used here are broadly representative of a wide range of semelparous marine invertebrate species, the application of these data to the models is intended to serve as an illustration of how EJP can affect relative fitness, and not to predict the absolute fitnesses of a given set of life history traits.

The data in Table 1 were applied to the mathematical models outlined above (Eqs. $4 \& 5$ ). Because post-

Table 2. Developmental characteristics of opisthobranch molluscs. $\mathrm{P}=$ planktotrophic $\mathrm{L}^{\mathrm{L}}=$ lecithotrophic

\begin{tabular}{|c|c|c|c|c|c|c|}
\hline \multirow[t]{2}{*}{ Species } & \multirow[t]{2}{*}{$\begin{array}{l}\text { Development } \\
\text { type }\end{array}$} & \multirow{2}{*}{$\begin{array}{l}\text { Ovum } \\
\text { diameter } \\
\qquad(\mu \mathrm{m})\end{array}$} & \multicolumn{2}{|c|}{$\begin{array}{c}\text { Development } \\
\text { time \& temperature }\end{array}$} & \multirow{2}{*}{$\begin{array}{l}\text { Standardised } \\
\text { development } \\
\text { time at } 10^{\circ} \mathrm{C}^{\mathrm{a}} \\
\text { (d) }\end{array}$} & \multirow[t]{2}{*}{ Source ${ }^{b}$} \\
\hline & & & (d) & $\left({ }^{\circ} \mathrm{C}\right)$ & & \\
\hline Acteocina canaliculata & $P$ & 91.5 & 17.0 & 19.0 & 34.39 & (1) \\
\hline Adalaria proxima & $\mathrm{L}$ & 165.0 & 32.3 & 10.0 & 32.30 & (2) \\
\hline Aplysia californica & $\mathrm{P}$ & 85.0 & 43.0 & 22.0 & 110.02 & (1) \\
\hline Aplysia dactylomela & $P$ & 90.0 & 38.0 & 25.0 & 122.97 & (1) \\
\hline Aplysia juliana & $\mathrm{P}$ & 77.0 & 35.0 & 25.0 & 113.26 & (1) \\
\hline Archidoris pseudoargus & $\mathrm{P}$ & 149.0 & 62.0 & 10.0 & 62.00 & (2) \\
\hline Berthelina limax & L & 80.0 & 35.0 & 20.0 & 76.57 & (1) \\
\hline Bursatella leachi plei & $\mathrm{P}$ & 87.0 & 26.0 & 25.0 & 84.13 & (1) \\
\hline Capellinia exigua & $L$ & 120.0 & 12.0 & 23.0 & 33.20 & (1) \\
\hline Cuthona adyarensis & $\mathrm{L}$ & 180.0 & 5.0 & 23.0 & 13.83 & (1) \\
\hline Discodoris erythraensis & $\mathrm{L}$ & 140.0 & 18.5 & 19.0 & 37.43 & (1) \\
\hline Dolabella auricularia & $P$ & 92.0 & 40.5 & 25.0 & 131.06 & (1) \\
\hline Doridella obscura & $P$ & 65.0 & 13.0 & 25.0 & 42.07 & (1) \\
\hline Doridella steinbergae & $P$ & 80.0 & 34.0 & 13.5 & 44.72 & (2) \\
\hline Eolidina mannarensis & $\mathrm{L}$ & 150.0 & 9.0 & 30.0 & 43.08 & (1) \\
\hline Facelina fusca & L & 180.0 & 21.0 & 13.0 & 26.56 & (1) \\
\hline Haminaea callidegenita & $\mathrm{L}$ & 220.0 & 24.0 & 15.0 & 35.50 & (2) \\
\hline Hermissenda crassicornis & $\mathrm{P}$ & 65.0 & 40.0 & 13.0 & 50.59 & (2) \\
\hline Melibe leonina & $\mathrm{P}$ & 90.0 & 48.0 & 10.0 & 48.00 & (2) \\
\hline Melibe pilosa & $\mathrm{L}$ & 128.0 & 9.5 & 25.0 & 30.74 & (1) \\
\hline Melibe sp. & $\mathrm{P}$ & 72.0 & 24.0 & 25.0 & 77.66 & (1) \\
\hline Onchidoris bilamellata & $\mathrm{P}$ & 100.0 & 62.0 & 10.0 & 62.00 & (1) \\
\hline Onchidoris muricata & $\mathrm{P}$ & 90.0 & 71.8 & 10.0 & 71.80 & $(2)$ \\
\hline Phestilla melanobranchia & $P$ & 115.0 & 15.5 & 22.0 & 39.66 & (1) \\
\hline Phestilla sibogae & L & 156.0 & 10.0 & 25.0 & 32.36 & (1) \\
\hline Phidiana lycnaeus & $\mathrm{L}$ & 140.0 & 7.0 & 26.5 & 25.47 & (1) \\
\hline Phyllaplysia taylori & $\mathrm{L}$ & 153.0 & 24.0 & 16.0 & 38.39 & (2) \\
\hline Rostanga pulchra & $\mathrm{P}$ & 80.0 & 50.5 & 12.5 & 61.42 & $(1)$ \\
\hline Stylocheilus longicauda & $\mathrm{P}$ & 66.0 & 36.5 & 25.0 & 118.11 & (1) \\
\hline Tritonia diomedea & $\mathrm{P}$ & 87.0 & 49.0 & 11.0 & 52.99 & $(2)$ \\
\hline Tritonia hombergi & $L$ & 200.0 & 43.0 & 9.5 & 41.35 & (1) \\
\hline
\end{tabular}


metamorphic growth of Adalaria proxima is approximately linear over time (Havenhand \& Todd 1988a), the data for this species have been applied to the linear growth model (Eq. 4). A. proxima larvae are lecithotrophic and no growth occurs during the larval period (Kempf \& Todd 1989), therefore larval growth rate $(\gamma)$ was set to zero in this evaluation. In contrast to $A$. proxima, Onchidoris muricata larvae are planktotrophic and post-metamorphic growth is curvilinear with time and approaches an exponential function (Havenhand \& Todd 1988a). Consequently the data for this species were used to evaluate the exponential growth model (Eq. 5).

Post-metamorphic growth rates, weights at maturity, and weight-specific fecundities were obtained from Havenhand (1986), and Havenhand \& Todd (1988a, b). The diameters of the ova of Adalaria proxima and Onchidoris muricata are 165 and $90 \mu \mathrm{m}$ respectively (Todd \& Havenhand 1985). The volume of A. proxima ova is therefore approximately 6 times that of $O$. muricata ova. Kempf \& Todd (1989) give the weight of a newly hatched A. proxima larva to be ca $1 \mu \mathrm{g}$, and consequently the weight of a newly hatched $O$. muricata larva was estimated as approximately one-sixth that of A. proxima. For convenience this value was rounded to 1 significant digit $\left(\approx 0.2 \mu g_{\text {; }}\right.$ Table 1$)$.

Pre-metamorphic mortality rates were calculated from literature values for the embryonic and larval mortality rates of molluscs (Rumrill 1990), and interpolations of observed embryanic and larval development times (Todd \& Havenhand 1985, Havenhand 1986). Estimates of benthic (post-metamorphic) mortality rates are not readily available for nudibranchs. Todd (1979) does provide data for Onchidoris bilamellata and gives an instantaeous mortality rate of $2.37 \% \mathrm{~d}^{-1}$, although additional data presented correspond to daily mortality rates of approximately $1 \% \mathrm{~d}^{-1}$. In order to obtain positive values of $x$ and thereby facilitate presentation of the results, the post-metamorphic mortality estimates used here are an order of magnitude lower than this (Table 1). This difference does not substantially affect the general results of the model (see 'Sensitivity analysis' below).

Studies of larval growth in molluscs generally indicate linear increases in shell dimension with time (Bayne 1983). This implies curvilinear increase in body mass over time. For example, Sprung (1984) found that the mass of veligers of the blue mussel Mytilus edulis increased at a rate equivalent to $9.1 \%$ $\mathrm{d}^{-1}$, and Kempf (1982; cited in Kempf \& Todd 1989) provides data for the (planktotrophic) larvae of the opisthobranch Aplysia juliana which yield a specific growth rate of $9.8 \% \mathrm{~d}^{-1}$ (although these authors do not state the form of the growth curve). Equivalent data are not available for opisthobranch molluscs and therefore on the basis of these values, larval growth rate $(\gamma)$ of Onchidoris muricata was estimated to be $9.5 \% \mathrm{~d}^{-1}$ (Tabie 1 ).

\section{RESULTS}

The potential importance of the egg-to-juvenile period (EJP) to the overall fitness of a lineage is illustrated in Fig. 2. This shows the relationship between the intrinsic rate of increase, $r$, and EJP $(=\theta T)$ using the data for nudibranch molluscs (Table 1). The solid line in Fig. 2 (linear post-metamorphic growth) indicates that for all values of EJP greater than $40 \mathrm{~d}$, dny reduction in EJP causes an increase in $r$. Fitness is maximised at ca $40 \mathrm{~d}$ and as EJP declines beyond this point fitness declines slowly at first but then rapidly falls to zero. Precise evaluation of this model demonstrates the magnitude of selective benefit (change in $r$ ) which may accrue from a given change in life-history traits: a $10 \%$ reduction in EJP (from 100 to 90 d) yields a $3.6 \%$ increase in $r$ (from 0.02409 to 0.02495 )

The importance of the post-metamorphic growth curve to the $r: \theta T$ relationship is reflected in the difference between the the 2 lines in Fig. 2. The exponential growth model (hatched line, Fig. 2) also shows an upward convex curve, but with lower overall $r$ values and with a maximum $r$ at $30 \mathrm{~d}$. The changes in fitness which accompany a given change in EJP are greater however: analysis of this model shows that a $10 \%$ reduction in EJP (from 100 to $90 \mathrm{~d}$ ) yields a $12.7 \%$ increase in $r$ (from 0.01231 to 0.01387 ).

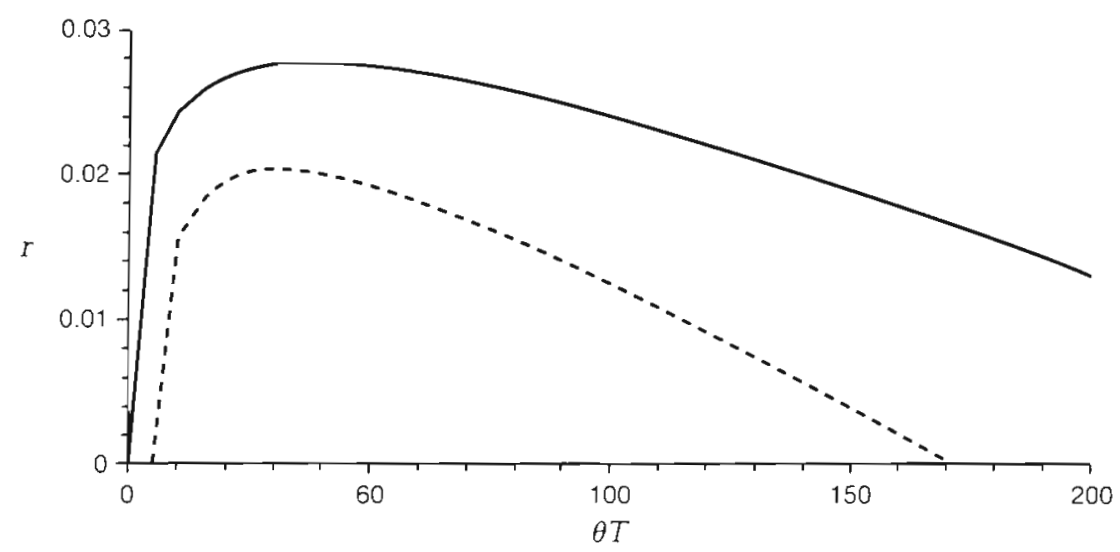

Fig. 2. Effect of variation in the egg-to-juvenile period ( $E J P=\theta T$ ) on the intrinsic rate of increase $(r)$. Solid line: linear growth model (Eq. 4); dashed line: exponential growth model (Eq. 5). (Parameters as given in Table 1; $T=365$ d) 
With specific reference to the species for which sample data were obtained, the results of these models predict that very different selective pressures operate on the 2 nudibranch species investigated here. Adalaria proxima naturally has a ca 34 d EJP at $10^{\circ} \mathrm{C}$ (Thompson 1958, Todd \& Havenhand 1985). Therefore this species would lie close to the peak in $r$ seen in Fig. 2 (solid line; linear post-metamorphic growth) in a region of the curve where changes in EJP do not result in large changes in fitness. In contrast, Onchidoris muricata has an EJP of ca $71 \mathrm{~d}$ at $10^{\circ} \mathrm{C}$ (Todd \& Havenhand 1985) and therefore would be subject to a selective pressure to reduce EJP.

These results are entirely dependent on the input data, however the patterns shown hold true for all reasonable parameter values (see 'Sensitivity analysis' below). It is clear therefore that under ecologically realistic conditions abbreviation of EJP may result in substantially greater fitness, and that at progressively shorter EJPs a fitness maximum is reached below which any further reduction in EJP results in loss of fitness.

The impact of EJP on fitness is not limited to the fixed life cycle duration of $365 \mathrm{~d}$ shown in Fig. 2: fitness is affected by EJP at all life cycle durations. However changing life-cycle length $(T)$ alters both the elevation and degree of curvature of the relationship shown in Fig. 2. This is illustrated for the linear growth model (Eq. 4) in Fig. 3 and for the exponential model (Eq. 5) in Fig. 4.

\section{Linear post-metamorphic growth (Eq. 4)}

The curvilinear relationship between fitness $(r)$ and egg-to-juvenile period $(E J P=\theta T)$ seen in Fig. 2 applies to all life-cycle durations from 0 to $700 \mathrm{~d}$ (Fig. 3). However the maximal ('peak') fitness seen in that relationship increases and becomes more pronounced as life-cycles become shorter. Consequently fitness increases exponentially with decreasing life-cycle duration $(T)$. The EJP at which this maximum occurs (the 'optimum' EJP) also depends on the length of the life-cycle - this optimum decreases with decreasing life-cycle duration.

As EJP increases away from the optimum value, fitness declines gradually at first and then more rapidly. This applies to all life-cycle durations although, as noted earlier, this effect becomes less marked as life-cycle duration increases. In contrast, as EJP decreases away from the optimum, fitness falls off relatively rapidly to less than zero at all lifecycle durations. This decline (which is also present in the exponential growth model; see below) is primarily due to the relationship between ovum diameter, $\varepsilon, E J P$, and fecundity outlined earlier: at such short EJPs fecundity is very low with the result that mortality causes complete loss of a cohort before reproductive maturity is reached. It should be noted, however, that the fecundities estimated for such short EJPs are extrapolated beyond the range of the data in Table 2 and therefore these results should be interpreted with caution (but see 'Sensitivity analysis' below)

Thus, the optimum egg-to-juvenile period is shorter when life cycles are shorter, fitness is greater when life-cycles are shorter, and a given change in egg-tojuvenile period influences fitness far more when lifecycles are short than when they are long (Fig. 3).

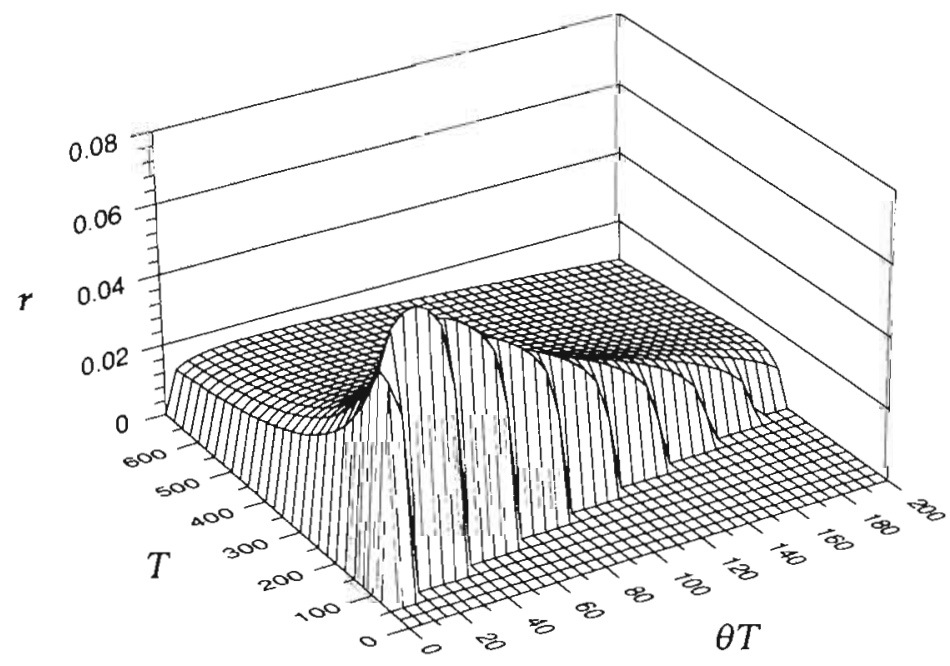

Fig. 3. Response of the intrinsic rate of increase $(r)$ to variation in eggto-juvenile period $(\theta T)$ and life cycle duration $(T)$. Linear growth model (Eq. 4). For presentational purposes, negative values of $r$ are not shown. (Parameters as given in Table 1)

\section{Exponential post-metamorphic growth (Eq. 5)}

The results from the exponential growth model are qualitatively similar to those of the 'linear' model (Eq. 4): fitness ( $r$ ) increases as EJP $(\theta T)$ decreases until a maximum fitness is reached at an 'optimal' EJP. At EJPs less than this optimum value, fitness rapidly declines to zero. Similarly, the curvature of the relationship between $I$ and $\theta T$ increases as life cycle duration ( $T$ ) declines so that the optimal EJP is more clearly defined when life-cycles are short (Fig. 4). However, unlike the linear model, fitness always increases as life-cycle duration increases. When EJP is short, this increase is initially rapid but leads to a plateau where further increases in life-cycle duration do not yield significantly greater increases in fitness. As EJP increases, however, the slope of the relationship between life-cycle duration and fitness becomes more constant (Fig. 4). 


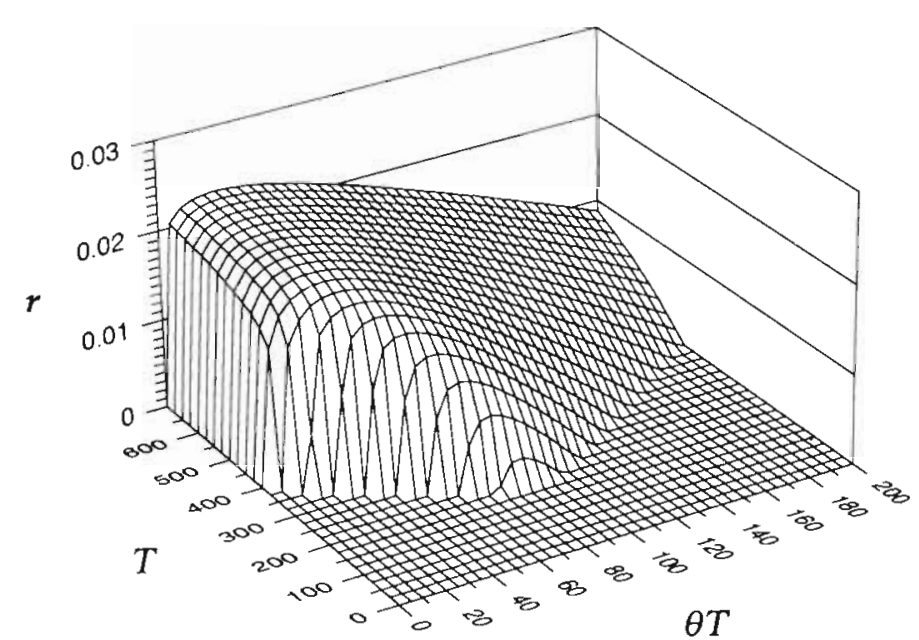

Fig. 4. As for Fig. 3, but exponential growth model (Eq. 5). (Note different scale for $r$ )

Further differences between this model and the linear model are evident from Fig. 4: although the highest fitnesses are attained at shorter EJPs (as in the linear model), fitness here is maximised at maximal life-cycle durations (the opposite result to the linear model; cf. Figs. $3 \& 4$ ). Thus, as life-cycle duration declines, so the maximal possible fitness (for that life-cycle) declines and the optimal EJP (at which that maximal fitness is obtained) increases. This results in a response surface on which increase in life-cycle duration will always result in increased fitness, but because the optimal EJP increases with decreasing life-cycle duration, the fitness consequences of reduced EJP are not so readily predicted.

These differences between the linear and the curvilinear growth models are due primarily to differences between the form of the post-metamorphic growth curves - in the linear model shorter life-cycles result in greater fitness because growth in offspring numbers per generation is exponential whereas growth in adult bady size (and fecundity) over time is linear. In contrast, when growth within the life-cycle is exponential, the relative fitness of early versus late reproduction (i.e. whether fitness increases or decreases with increasing $T$ ) will depend on the balance between specific growth and mortality rates. Nonetheless, varying larval growth rates (for example) can significantly influence the results of the model. In order to assess this and the impact of variation in other input parameters a detailed analysis of the sensitivity of the model was conducted.

\section{SENSITIVITY ANALYSIS OF THE MODEL}

The sensitivity of the models to variation in the values of input parameters is shown in Tables $3 \& 4$. In all cases changes in the parameters values were chosen to represent the extremes of ecological and biological realism for the species involved. (When testing any given parameter, all other parameter values were held fixed at the levels shown in Table 1).

\section{Linear post-metamorphic growth (Eq. 4)}

Fitness (change in $r$ ) is most sensitive to changes in the post-metamorphic growth rate, $g$, the premetamorphic mortality rate, $\mu_{1}$ and the larval growth rate, $\gamma$, (Table 3 ). The results of the model are robust to changes in the other parameters including substantial changes in the allometric relationship between ovum diameter and EJP (Table 3).

Increases in the post-metamorphic growth rate, $g$, result in marked accentuation of the peak in $r$, whilst decreases in $g$ flatten the surface. The values of $g$ used here (Table 1) were obtained for laboratory held animals fed ad libitum on the preferred diet (Havenhand \& Todd 1988a, b) and therefore growth rates in the field would probably be lower than that tested here. This would result in lower overall fitness (Table 3).

As one would predict, increases in the pre-metamorphic mortality rate, $\mu_{1}$, steepen the relationship between $\theta T$ and $r$ and amplify the fitness benefits of decreased EJP. It is unlikely that pre-metamorphic mortality rates in the field would substantially exceed the values tested here (Table 3): Rumrill (1990) cites daily mortality rates for encapsulated mollusc embryos ranging from 0.005 to $0.07 \mathrm{~d}^{-1}$, and for veligers ranging from 0.13 to $0.28 \mathrm{~d}^{-1}$. Given that Adalaria proxima has extended embryonic development and a relatively brief larval period of only a few days (Thompson 1958, Todd \& Havenhand 1985 , Kempf \& Todd 1989) it is improbable that $\mu_{l}$ would exceed $10 \% \mathrm{~d}^{-1}$ for this species (Tables $1 \& 3$ ).

The fitness consequences of variation in the 'larval' (pre-metamorphic) growth rate, $\gamma$, are substantial. Although Adalaria proxima does not grow during its larval period (Kempf \& Todd 1989), other marine invertebrate species may have both planktotrophic larvae and linear post-metamorphic growth. Therefore the evaluation of positive larval growth rates in this model is reasonable. (It should be remembered, however, that the inclusion of larval growth would require a longer larval period than the few days allowed here, and therefore, pre-metamorphic mortality rates would be correspondingly greater than those tested in this run of the model.) When $\gamma$ is increased to $5 \% \mathrm{~d}^{-1}$ a second peak in fitness occurs at $\theta T=200, T=200$ (Table 3). This peak creates an adaptive 'trough' in the surface 
Table 3. Sensitivity analysis (linear post-metamorphic growth; Eq. 4, Fig. 3)

\begin{tabular}{|c|c|c|}
\hline Parameter & Change & Result \\
\hline \multirow[t]{2}{*}{$W_{0}$} & $10 \times$ & No perceptible change \\
\hline & $W_{0}=0$ & No perceptible change \\
\hline \multirow[t]{2}{*}{$\gamma$} & $\gamma=0.04$ & No perceptible change \\
\hline & $\gamma=0.05$ & $\begin{array}{l}\text { Second peak appears in surface such that } \\
r \text { is maximised at both } \theta T=0 \text { and } \theta T=200 \text {. } \\
\text { (Further minor increases in } \gamma \text { rapidly yield } \\
\text { a higher peak at } \theta T=200 \text { ) }\end{array}$ \\
\hline \multirow[t]{2}{*}{$\mu_{1}$} & $2 \times$ & $\begin{array}{l}\text { Steepens relationship between } r \text { and } \theta T \\
(r<0 \text { at all } \theta T>150) \text {. } \\
\text { Moves } r_{\max } \text { peak from } \theta T=20 \text { to } \theta T=15 \text {. } \\
\text { Reduces } r_{\max } \text { peak by } \sim 0.01\end{array}$ \\
\hline & $0.5 \times$ & $\begin{array}{l}r: \theta T \text { relationship becomes more shallow }\left(r_{\max }\right. \\
\text { peak less well defined }-r \text { is positive at } \theta T=200, \\
T=700) . \text { Location of } r_{\max } \text { peak unchanged. } \\
\text { Increases } r_{\max } \text { peak by } \sim 0.005\end{array}$ \\
\hline \multirow[t]{2}{*}{$g$} & $2 \times$ & $\begin{array}{l}r_{\max } \text { peak more clearly defined. } \\
\text { Increases } r_{\max } \text { peak by } \sim 0.06 \\
r: \theta T \text { slope at } T=700 \text { unchanged. }\end{array}$ \\
\hline & $0.5 \times$ & Decreases $r_{\max }$ by $\sim 0.03(r<0$ for $T<125)$ \\
\hline \multirow[t]{2}{*}{$\mu_{\mathrm{b}}$} & $10 \times$ & $\begin{array}{l}\text { Depresses whole surface by } \sim 0.01 \mathrm{r} \text {. } \\
\text { Accentuates curvature of } r: T \text { relationship }\end{array}$ \\
\hline & $\mu_{\mathrm{b}}=0$ & Slight elevation of whole surface by $\sim 0.002 r$ \\
\hline \multirow[t]{2}{*}{$W_{\mathrm{m}}$} & $2 \times$ & Same effect as $0.5 \times g$ \\
\hline & $0.5 \times$ & Same effect as $2 \times g$ \\
\hline \multirow{2}{*}{$\begin{array}{l}\text { Fecundity } \\
\text { exponent } \\
\text { in ovum dia- } \\
\text { meter:EJP } \\
\text { regression }{ }^{\text {a }}\end{array}$} & $2 \times$ & $\begin{array}{l}r_{\max } \text { peak less clearly defined. } \\
\text { Reduces } I_{\max } \text { by } \sim 0.01 . \\
\text { Moves } r_{\max } \text { peak from } \theta T=20 \text { to } \theta T=40 .\end{array}$ \\
\hline & $0.5 \times$ & $\begin{array}{l}r_{\max } \text { peak more clearly defined. } \\
\text { Increases } I_{\max } \text { by } \sim 0.01 \\
\text { Moves } r_{\max } \text { peak from } \theta T=20 \text { to } \theta T=5\end{array}$ \\
\hline a See text for & planatio & \\
\hline
\end{tabular}

similar to that of the linear model (above): the results are most susceptible to changes in the post-metamorphic specific growth rate, $g^{\prime}$, the pre-metamorphic mortality rate, $\mu_{1}$, and the larval growth rate, $\gamma$, (Table 4). However the direction of the response to given changes in those parameters is not the same as in the linear model.

Changing the specific growth rate $g^{\prime}$ by a factor of 2 alters the elevation of the entire surface in Fig. 4 but does not significantly alter the shape of the surface

The consequences of increasing premetamorphic mortality rate, $\mu_{1}$, are similar to those in the linear model (Tables $3 \& 4$ ): doubling larval mortality steepens the relationship between $r$ and $\theta T$ and therefore increases the fitness benefits of any given reduction in EJP. However, this change also results in zero fitness for all life-cycle durations less than $300 \mathrm{~d}$, or egg-to-juvenile periods longer than $90 \mathrm{~d}$ (Table 4). In stark contrast to the effect of similar changes in the linear model however, reducing larval mortality by a factor of 2 results in maximal fitness being obtained at minimal rather than maximal life-cycle durations (cf. Fig. 4). This creates a ridge of maximum fitness along the edge of the surface where $\theta T=T(r \approx 0.05)$. Again, this ridge arises because the ratio between larval mortality and growth has decreased (mortality has declined whilst growth has remained constant). If, as in the analysis of the linear model earlier, this ratio is increased back toward its original level by reducing growth rate by $2 \% \mathrm{~d}^{-1}$, then fitness is no longer maximised at minimal life-cycle durations.

between this peak and that seen in Fig. 2. Under these circumstances both low and high EJPs yield higher fitness than intermediate values. This is a result of increasing the larval growth rate relative to larval mortality - if the ratio between larval mortality and growth is increased back toward its original level by elevating pre-metamorphic mortality rates to $0.07 \mathrm{~d}^{-1}$ (only $2 \% \mathrm{~d}^{-1}$ greater than the value used in this run of the model), this second peak disappears completely.

\section{Exponential post-metamorphic growth (Eq. 5)}

The response of the exponential growth model (Fig. 4) to variation in the input parameters is broadly
Analogous changes occur to the response surface in Fig. 4 if larval growth is more rapid. Increasing the larval growth rate, $\gamma$, by ca $1.5 \times$ (to $0.15 \mathrm{~d}^{-1}$ ) produces a peak in the surface of Fig. 4 such that maximal fitness, $r$, is obtained at minimum life-cycle durations. Reducing larval growth rate to $0.14 \mathrm{~d}^{-1}$ removes this peak and restores a surface broadly similar to that seen in Fig. 4 (Table 4).

It is clear from these results that the impact of eggto-juvenile period on fitness may be heavily influenced by the form of the post-metamorphic growth curve. As a final test of the robustness of the model presented here, alternative growth functions were evaluated. In these tests none of the assumptions of the model were 
Table 4. Sensitivity analysis (exponential post-metamorphic growth; Eq. 5 , Fig. 4)

\begin{tabular}{|c|c|c|}
\hline Parameter & Change & Result \\
\hline \multirow[t]{2}{*}{$W_{0}$} & $10 \times$ & $\begin{array}{l}\text { Elevates whole surface by } \sim 0.004 r \\
r_{\max } \text { peak more clearly defined. } \\
r \text { is positive at lower } T(r>0 \text { at } T>100)\end{array}$ \\
\hline & $W_{0}=0$ & $\begin{array}{l}\text { Depresses whole surface by } \sim 0.004 r \\
r_{\max } \text { peak less clearly defined. } \\
r<0 \text { at } T<300\end{array}$ \\
\hline \multirow[t]{3}{*}{$\gamma$} & $\gamma=0.14$ & $\begin{array}{l}r: T \text { relationship reaches plateau } \\
(r \approx 0.025 \text { at } T>200) \\
r: \theta T \text { still upwardly convex at } T<200 \\
\text { [at all values of } \theta T, r \text { declines as } T \text { declines] }\end{array}$ \\
\hline & $\gamma=0.15$ & $\begin{array}{l}\text { New peak appears in surface such that } \\
r \text { is maximised at } T=100, \theta T=100(r \approx 0.033) \text {. } \\
\text { [r declines as } T \text { increases }]\end{array}$ \\
\hline & $\gamma=0.05$ & $\begin{array}{l}I_{\max } \text { peak more clearly defined. } \\
\text { Elevation of } r_{\max } \text { unchanged. } \\
\text { Moves } r_{\max } \text { peak from } \theta T=25 \text { to } \theta T=15 \text {. } \\
r<0 \text { at } \theta T>190, T<300\end{array}$ \\
\hline \multirow[t]{2}{*}{$\mu_{1}$} & $2 x$ & $\begin{array}{l}r_{\text {max }} \text { peak more clearly defined. } \\
\text { Decreases } r_{\max } \text { by }=0.004 \\
\text { Moves } r_{\max } \text { from } \theta T=25 \text { to } \theta T=10 \\
r<0 \text { at } \theta T>90, T<300\end{array}$ \\
\hline & $0.5 \times$ & $\begin{array}{l}r \text { now maximised along border } \theta T=T(r=0.05) \\
{[r \text { declines as both } \theta T \text { and } T \text { decline }]}\end{array}$ \\
\hline \multirow[t]{2}{*}{$g^{\prime}$} & $2 \times$ & $\begin{array}{l}\text { Elevates whole surface by } \sim 0.02 r \\
r<0 \text { at } T<125\end{array}$ \\
\hline & $0.5 x$ & $\begin{array}{l}\text { Depresses whole surface by } \sim 0.007 r \text {. } \\
r<0 \text { at } T<250\end{array}$ \\
\hline \multirow[t]{2}{*}{$\mu_{\mathrm{b}}$} & $10 \times$ & $\begin{array}{l}\text { Reduces } r_{\text {rlad }} \text { by } \sim 0.01 \\
r: T \text { relationship less steep at all values of } \theta T \\
r \text { still positive at same combinations of } \theta T \& T\end{array}$ \\
\hline & $\mu_{\mathrm{b}}=0$ & $\begin{array}{l}\text { Increases } r_{\max } \text { by } \sim 0.001 \\
r: T \text { relationship steeper at all values of } \theta T \\
r \text { still positive at same combinations of } \theta T \& T\end{array}$ \\
\hline \multirow[t]{2}{*}{$W_{\mathrm{m}}$} & $10 \times$ & $\begin{array}{l}r_{\max } \text { unchanged } \\
\text { Moves whole surface back }(r<0 \text { at } T<250)\end{array}$ \\
\hline & $0.5 \times$ & $\begin{array}{l}T_{\max } \text { unchanged } \\
\text { Moves whole surface forward }(r<0 \text { at } T<125 \text { ) }\end{array}$ \\
\hline \multirow{2}{*}{$\begin{array}{l}\text { Fecundity } \\
\text { exponent } \\
\text { in ovum dia- } \\
\text { meter: EJP } \\
\text { regression }{ }^{\text {a }}\end{array}$} & $2 x$ & $\begin{array}{l}r_{\max } \text { peak less clearly defined. } \\
\text { Reduces } r_{\max } \text { by } \sim 0.002 . \\
\text { Moves } r_{\max } \text { peak from } \theta T=20 \text { to } \theta T=4.0 \text {. }\end{array}$ \\
\hline & $0.5 x$ & $\begin{array}{l}r_{\max } \text { peak more clearly defined. } \\
\text { Increases } r_{\max } \text { by }-0.002 \text {. } \\
\text { Moves } r_{\max } \text { peak from } \theta T=20 \text { to } \theta T=5\end{array}$ \\
\hline & lanoti & \\
\hline
\end{tabular}

examples given above) yielded results which were qualitatively similar to those obtained from the linear growth model (Eq. 4. Fig. 3), although absolute rates of increase were slightly lower (data not shown).

\section{DISCUSSION}

Variation in the egg-to-juvenile period (EJP) has a significant effect on the fitness (change in $r$ ) of a lineage and this becomes increasingly important in shorter life cycles (Figs. 3 \& 4). This effect is mediated primarily by pre- and post-metamorphic growth and mortality rates, however weight-specific fecundity and size at maturity also intluence this relationship.

In all cases an 'optimal' EJP exists at which $r$ is maximised. For annual lifecycles this optimum is relatively broad and occurs at 30 or 40 d respectively for exponential or linear post-metamorphic growth. For EJPs longer than this optimum, reduction of the egg-to-juvenile period results in substantial increases in fitness. For EJPs shorter than this optimum, fitness declines rapidly with declining EJP. The selective benefit which derives from a given change in EJP will therefore depend on the initial EJP. Selection should therefore operate to reduce EJP when this is longer than the optimum value. We have already seen that the incidence of lecithotrophy is inversely related to EJP (Table 2, refs. above, see Fig. 5), and consequently the selective pressure to reduce EJP toward the optimum is equivalent to a selective pressure for the evolution of lecithotrophy.

The observed increases in $r$ which accompany a $10 \%$ decrease in EJP (from 100 to $90 \mathrm{~d}$ ) are substantial (4 to $13 \%$; Fig. 2; see 'Results'). This decrease is well within the range of egg-to-juvenile periods seen within laboratory cultures of full sibling batches of most marine invertebrate species (Strathmann 1987). The resulting changes in $r$ are broadly analogous to selection coefficients for shorter EJPs. Consequently the model predicts altered save for those relating to post-metamorphic growth. The substitution of sigmoid growth curves into the model (Logistic or Gompertz curves using parameter values appropriate for the nudibranchs in the that the selective pressure to evolve an abbreviated EJP may often be very strong. Given that the results of the model are relatively insensitive to the values of the input parameters (Tables $3 \& 4$ ), this result is not criti- 


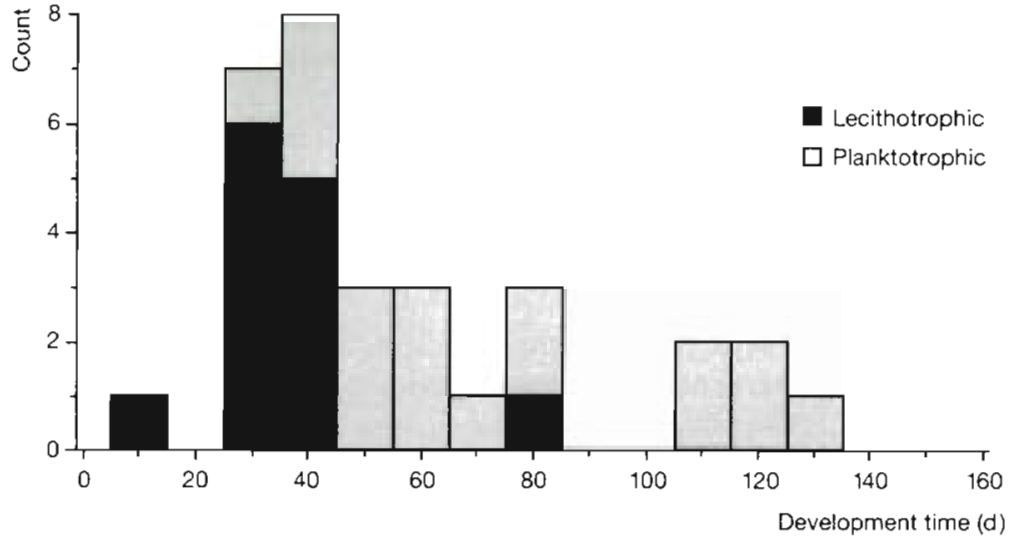

Fig. 5. Standardised development times from egg-to-juvenile for 31 species of opisthobranch mollusc (data taken from Table 1)

cally dependent on the accuracy of the data used here (Table 1).

The model allows several predictions to be made with regard to the selective advantages of changes in life cycle duration or EJP. For example, the existence of a predicted optimum egg-to-juvenile period can be tested: if planktotrophy (and hence long EJP) is the ancestral condition, I would predict that species of opisthobranch with life-history characteristics similar to those in Table 1 would have evolved EJPs at, or close to this optimum, and that development of these larvae would be primarily lecithotrophic. Furthermore, selection against EJPs shorter than the predicted optimum would be strong (the slope of the $r: \theta T$ relationship is steep for short EJPs; Fig. 2), whereas selection against EJPs longer than the optimum would be relatively weak. Consequently I would additionally predict that few if any species exhibit EJPs shorter than the optimum, but several species may well have EJPs longer than the optimum. This latter prediction would also account for species which either continue to exhibit the ancestral condition or are in the process of evolving toward the optimal EJP.

These predictions can be tested using the data presented in Table 2. [Although these data were used to derive the ovum diameter: EJP relationship which has been used in the model, the results of the model are insensitive to the parameters of that relationship (Tables 3 \& 4). Therefore this data set is effectively independent of that used to evaluate the model.] Fig. 5 shows a frequency distribution of EJPs for the 31 species of opisthobranch in Table 2. The modal EJP for these species is $35 \mathrm{~d}$, and the majority of species at the modal EJP are lecithotrophs. Although the predicted optimum is broad (Fig. 2), these data show remarkable correspondence with the predictions of the model. In addition, although several species have EJPs far longer than the predicted optimum, only one (Cuthona ad- yarensis) has an EJP less than the optimum. Despite the fact that some of the species in Table 2 exhibit life-history characteristics which differ from those of the nudibranchs with which the model was evaluated, these data provide strong preliminary support for the model.

Further predictions can be made with respect to the duration of the life-cycle. For the exponential model (Fig. 4), $r$ initially increases more rapidly with increasing life cycle duration $(T)$ than with decreasing EJP $(\theta T)$. Therefore, a given increase in life cycle duration would be selectively more advantageous than an equivalent decrease in EJP for any organism in this region of the surface. This effect rapidly declines with increasing life cycle duration, however, such that in most cases the selective advantages of reducing EJP are greater than those of increasing life cycle duration by the same amount. In contrast, the peak in $r$ which is reached at an optimum life cycle length in the linear model (Fig. 3) means that any lineage which is already at or near this optimum will face a strong selective pressure to retain that lifecycle duration. Nonetheless selection may still operate to optimise the EJP within that life-cycle dependent on the location of the lineage on the $r: \theta T$ plane.

It should be stressed that these changes are not necessarily an evolutionary option for any given lineage. The adaptive value of an 'optimal' egg-tojuvenile period will depend entirely on the evolutionary ability of a lineage to reach that optimum. Increases in fitness may be achieved by reducing EJP irrespective of the location or existence of the optimum EJP. Appropriate mutations and life-history character tradeoffs must combine before the opportunity to evolve in this manner can arise. Furthermore, extrinsic factors such as the seasonal availability of prey may modify the selective benefit of such increases in $r$ so that reduction in life cycle length or EJP (for example) may be disadvantageous (Todd \& Doyle 1981, Yoshioka 1986).

As in all models, these predictions rest on the validity of the assumptions made at the outset. In most cases, those assumptions were simplifications for the purpose of illustrating the model. For example, the assumption of complete hermaphroditic semelparity was adopted for mathematical simplicity. Adalaria proxima and Onchidoris muricata actually reproduce over a period of several weeks prior to post-reproductive death (Havenhand \& Todd 1988a). Thus, within the context of the example given here, life cycle duration may be fractionally longer than generation time. This discrepancy has resulted in a marginal underestimation of 
fitness (Eqs. $3 \& 4$ ) but this would not materially alter the shapes of the surfaces in Figs. $3 \& 4$.

The impact of the remaining assumptions concerning the input parameters (fixed mortality rates, fixed growth rates, allometry of reproduction and body size) has been evaluated in the sensitivity analysis (see above; Tables 3 \& 4). Two-fold, and sometimes 10-fold, changes in these parameters did not qualitatively alter the predictions of the model. Consequently, any errors in the magnitude of the parameter values used (Table 1) are unlikely to be important. The effects of temporal variation in mortality or growth rates have not been examined however. The mortality and growth rates used here are stage-specific rather than age-specific. Although the use of age-specific mortality schedules (for example) might add to the accuracy of the predictions, such schedules are rarely available for marine invertebrates, and none are applicable to the models presented here. Moreover, it is unclear whether the added complexity of such schedules would substantially alter the conclusions.

Linear and exponential post-metamorphic growth functions were used here because they are mathematically simple and applicable to the data for (semelparous) nudibranch molluscs with which the model is evaluated. These growth patterns have been shown to be typical for opisthobranch molluscs (Havenhand \& Todd 1988a), and Calow (1981) suggests that exponential growth occurs in many species of invertebrate - particularly in semelparous species. Since most semelparous species are relatively short lived, and the influence of abbreviated EJP is greater in short duration life cycles (see 'Results'), these growth forms are particularly appropriate. Although linear and exponential growth can also be found in modular organisms (Sebens 1987), curvilinear growth to an asymptotic size is reported to be the most common pattern for marine invertebrates (Yamaguchi 1975, Calow 1981, Ebert 1982, Sebens 1987). The results of the sensitivity analysis suggest, however, that such curves does not produce response surfaces which differ substantially from those obtained with the simpler linear growth model. Therefore it is reasonable to expect that the fitness benefits of reduced EJP predicted here would apply to a wide range of organisms

Werner (1986) hypothesised that the ratio of mortality to growth rates in the pre-metamorphic and postmetamorphic habitat determines the timing of metamorphosis. The sensitivity analysis conducted here shows that manipulation of larval growth and mortality rates produces results which are in accordance with those predictions (Tables $3 \& 4$ ). In both the linear and exponential growth models, decreases in the ratio of larval mortality: growth rates produce a peak in fitness where $\theta T$ approaches $T$. Under these circumstances the model is predicting that lineages exhibiting these traits grow to reproductive maturity before metamorphosis. Thus the tradeoff between pre-metamorphic versus post-metamorphic mortality: growth is such that metamorphosis to the 'adult' habitat does not occur. Unlike Werner's hypothesis, the model presented here does not require metamorphosis for the attainment of reproductive maturity. Indeed these results converge on the predictions of Roughgarden's (1989) model in which high pre-metamorphic growth rates (and concomitantly low mortality) produce a strong selective pressure for the evolution of neoteny and a holoplanktonic life cycle.

Planktotrophic larval development is generally accepted to be ancestral in most phyla (Jägersten 1972, Strathmann 1985, 1986). The benefits of reducing EJP illustrated here therefore add to the wide variety of selective pressures which may play a role in the evolution of lecithotrophy from the ancestral type. Previous authors have emphasised the importance of survivorship, adult diet, retention at favourable sites, energetics and body size in this process (e.g. Vance 1973, Chia 1974, Christiansen \& Fenchel 1979, Clark et al. 1979, Johannesson 1988). Although the evolution of lecithotrophy may result in greater fitness, the simultaneous reduction in larval dispersive capacity may affect the long-term durability (sensu Endler 1986) of the species by rendering it more susceptible to local extinctions, for example. The balance between these factors will vary between species and will depend not only on the dispersive capacity of the larva, but also on the ecology of the larval and adult stages (e.g. Hansen 1978). Communities resulting from this process would therefore be a mixture of species which retain the ancestral larval type, suffer low fitness, but have geological longevity and species which evolve a 'fitter' larval type (short EJP, lecithotrophy) but suffer greater risk of extinction due to reduced dispersal.

The problems of determining post hoc the selective pressures which brought about the evolution of lecithotrophy in any given case may often be intractable. Nevertheless, I suggest that in many instances strong demographic responses to variation in the EJP will have combined with these other pressures to shape the evolution of larval types. For example, Strathmann \& Strathmann (1982) present an elegant allometric explanation of how small individuals may be pre-adapted to brooding. The model presented here emphasizes the importance of brooding in small individuals: brooded larvae are almost invariably lecithotrophic and are therefore likely to have a shorter EJP than their planktotrophic counterparts (Figs. $1 \& 5$ ). Since small size at reproduction may result from short life cycles, and since the model reveals that selection for an abbreviated EJP is greater when life cycle duration is 
shorter (Figs. 3 \& 4), some small species which brood their larvae may be small because they reproduce at an early age (or small size), have a short EJP, and thereby maximise their intrinsic rate of increase. This mechanism would operate independently of, but in parallel to, that described by Strathmann \& Strathmann (1982).

The results of the models presented here demonstrate clearly that in species with short life cycles, variation in EJP can significantly affect post-larval demographics, and consequently influence fitness. By illustrating a potentially important selective pressure, this model may explain the evolution of lecithotrophic larval development by a mechanism which has previously been overlooked.

Acknowledgements. This paper resulted from thoughtprovoking meetings with the Evolutionary Ecology Discussion group at the Friday Harbor Labs., University of Washington, and from conversations with F. S. Chia, and C. D. Todd. I thank D. R. Levitan and G. A. Wray for many helpful comments, and particularly A. R. Palmer, C. W. Petersen, R. R. Strathmann and 3 anonymous reviewers for improvements to earlier drafts of this manuscript. The author was supported by a NATO Postdoctoral Award from the Natural Environment Research Council (UK) (Award No. GT8/F/89/ALS/1). I am especially grateful to Prof. A. O. D. Willows, Director, Friday Harbor Labs., University of Washington, for the provision of excellent facilities and support without which completion of this work would not have been possible.

\section{LITERATURE CITED}

Ayal, Y., Safriel, U. N. (1982). I-curves and the cost of the planktonic stage. Am. Nat. 119: 391-401

Bayne, B. L. (1983). Physiological ecology of marine molluscan larvae. In: Verdonk, N. H., van den Biggelaar, J. A. M., Tompa, A. S. (eds.) The Mollusca, Vol. 3, Development. Academic Press, New York, p. 299-343

Begon, M., Harper, J. L., Townsend, C. R. (1990). Ecology: individuals, populations and communities. Blackwell Scientific, Oxford

Calow, P. (1981). Invertebrate biology: a functional approach. Croom Helm, London

Calow, P. (1983). Life cycle patterns and evolution. In: RussellHunter, W. D. (ed.) The Mollusca, Vol. 6, Ecology. Academic Press, New York, p. 649-678

Chia, F.-S. (1974). Classification and adaptive significance of developmental patterns in marine invertebrates. Thalassia jugosl. 10: 121-130

Christiansen, F. B., Fenchel, T M. (1979). Evolution of marine invertebrate reproductive patterns. Theor. Pop. Biol. 16: $267-282$

Clark, K. B., Busacca, M., Stirts, H. (1979). Nutritional aspects of development of the ascoglossan, Elysia cauze. In: Stancyck, S. E. (ed.) Reproductive ecology of marine invertebrates. Univ. South Carolina Press, Columbia, p. 11-24

Day, R., McEdward, L. (1984). Aspects of the physiology and ecology of pelagic larvae of benthic marine invertebrates. In: Steidinger, K. A., Walker, L. M. (eds.) Marine plankton life cycle strategies. CRC Press, Boca Raton, p. $93-120$

Ebert, T A. (1982). Longevity, life-history and relative body wall size in sea-urchins. Ecol. Monogr. 52: 353-394

Emlet, R. B., Mc Edward, L. R., Strathmann, R. R. (1987) Echinoderm larval biology viewed from the egg. In Jangoux, M., Lawrence, J. M. (eds.) Echinoderm studies, Vol. 2. Balkema, Rotterdam, p. 55-136

Endler, J. A (1986). Natural selection in the wild. Princeton Univ. Press, Princeton

Grahame, J., Branch, G. M. (1985). Reproductive patterns of marine invertebrates. Oceanogr. mar Biol. A. Rev. 23: 373-398

Hadfield, M. G., Switzer-Dunlap, M. (1984). Opisthobranchs. In: Tompa, A. S., Verdonk, N. H., van den Biggelaar, J. A. M. (eds.) The Mollusca, Vol. VII, Reproduction. Academic Press, New York, p. 209-350

Hansen, T. A. (1978). Larval dispersal and species longevity in lower Tertiary gastropods. Science 199: 885-887

Havenhand, J. N. (1986). The physiological ecology and life history strategies of the nudibranch molluscs Adalaria proxima (Alder \& Hancock) and Onchidoris muricata (Müller) (Gastropoda: Nudibranchia). Ph.D. thesis, Univ. St. Andrews, St. Andrews

Havenhand, J. N., Todd, C. D. (1988a). Physiological ecology of Adalaria proxima (Alder et Hancock) and Onchidoris muricata (Müller) (Gastropoda: Nudibranchia) I: Feeding, growth and respiration. J. exp. mar. Biol. Ecol. 118: $151-172$

Havenhand, J. N., Todd, C. D. (1988b). Physiological ecology of Adalaria proxima (Alder et Hancock) and Onchidoris muricata (Müller) (Gastropoda: Nudibranchia) II: Reproduction. J. exp. mar. Biol. Ecol. 118: 173-189

Jägersten, G. (1972). Evolution of the metazoan life cycle Academic Press, London

Johannesson, K. (1988). The paradox of Rockall: why is a brooding gastropod (Littorina saxatilis) more widespread than one having a planktonic larval dispersal stage (L. Littorea)? Mar. Biol. 99: 507-513

Kempf, S. C., Todd, C. D. (1989). Feeding potential in the lecithotrophic larvae of Adalaria proxima and Tritonia hombergi : an evolutionary perspective. J. mar biol. Ass U.K. 69: 659-682

Levin, L. A., Caswell, H., DePatra, K. D., Creed, E. L. (1987). Demographic consequences of larval developmental mode: Planktotrophy vs lecithotrophy in Streblospio benedicti. Ecology 68: 1877-1886

Lincoln, R. J., Boxshall, G. A., Clark, P. F. (1982). A dictionary of ecology, evolution and systematics. Cambridge Univ. Press, Cambridge

Miller, S. E. (in press). Larval period and its influence on postlarval life-history: a comparison of lecithotrophy and facultative planktotrophy in the aeolid nudibranch Phestilla sibogae. Mar. Biol.

Miller, S. E., Hadfield, M. G. (1990). Developmental arrest during larval life and life-span extension in a marine mollusc. Science 248: 356-358

Roughgarden, J. (1989). The evolution of marine life cycles. In: Feldman, M. W. (ed.) Mathematical evolutionary theory. Princeton Univ. Press, Princeton, p. 270-300

Rumrill, S. S. (1990). Natural mortality of marine invertebrate larvae. Ophelia 32: 163-198

Sebens, K. P. (1987). The ecology of indeterminate growth in animals. A. Rev. Ecol. Syst. 18: 371-407

Sprung, M. (1984). Physiological energetics of mussel larvae Mytilus edulis. I. Shell growth and biomass. Mar. Ecol Prog. Ser. 17: 283-293 
Strathmann, M. F. (1987). Reproduction and development of marine invertebrates of the northern Pacific coast. Univ. Washington Press, Seattle

Strathmann, R. R. (1977). Egg size, larval development, and juvenile size in benthic marine invertebrates. Am. Nat. 111: 373-376

Strathmann, R. R. (1985). Feeding and non-feeding larval development and life-history evolution in marine invertebrates. A. Rev. Ecol. Syst. 16: 339-361

Strathmann, R. R. (1986). What controls the type of larval development? Summary statement for the evolution session. Bull. mar. Sci. 39:616-622

Strathmann, R. R., Strathmann, M. F. (1982). The relation between adult size and brooding in marine invertebrates. Am. Nat. 119: 91-101

Thompson, T. E. (1958). The natural history, embryology, larval biology and post-larval development of Adalaria proxima (Alder \& Hancock) (Gastropoda: Opisthobranchia). Phil. Trans. R. Soc. Lond. Ser. B 242: 1-58

Thorson, G. (1946). Reproduction and development of Danish marine bottom invertebrates. Medd. Komm. Danm. Fisk. og Havunders., Ser. Plankton. 4: 1-523

Todd, C. D. (1979). The population ecology of Onchidoris

This article was presented by R. S. Scheltema, Woods Hole, Massachusetts, USA bilamellata (Gastropoda: Nudibranchia). J. exp. mar. Biol. Ecol. 41: 213-255

Todd, C. D. (1981). The ecology of nudibranch molluscs. Oceanogr. mar. Biol. A. Rev. 19: 141-234

Todd, C. D., Doyle, R. W. (1981). Reproductive strategies of marine invertebrates: a settlement timing hypothesis. Mar. Ecol. Prog. Ser. 4: 75-83

Todd, C. D., Havenhand, J. N. (1985). Preliminary observations on the embryonic and larval development of three dorid nudibranchs. J. mollusc. Stud. 51: 97-99

Underwood, A. J. (1974). On models for reproductive strategy in benthic marine invertebrates. Am. Nat. 108: 874-878

Vance, R. R. (1973). On reproductive strategies in marine invertebrates. Am. Nat. 107: 339-352

Werner, E. E. (1986). Amphibian metamorphosis: growth rate, predation risk, and the optimal size at transformation. Am. Nat. 128: 319-341

Yamaguchi, M. (1975). Estimating growth parameters from growth rate data: problems with marine sedentary invertebrates. Oecologia 20: 321-332

Yoshioka, P. M. (1986). Life history patterns of the dorid nudibranchs Doridella steinbergae and Corambe pacifica. Mar. Ecol. Prog. Ser. 31: 179-184

Manuscript first received: November 5, 1991

Revised version accepted: April 28, 1993 